\title{
HISTORICIDADE E ASPECTOS CENTRAIS DA POLÍTICA FEDERAL DO PATRIMÔNIO CULTURAL IMATERIAL: \\ UMA INTERPRETAÇÃO'
}

LEANDRO RIBEIRO DO AMARAL

Instituto do Patrimônio Histórico e Artístico Nacional (Iphan), Rio Branco, Acre, Brasil

DOI: http://dx.doi.org.br/10.11606/issn.1980-4466.v0i19p8-32

\section{RESUMO}

A prática de valoração e preservação de bens representativos do patrimônio histórico e artístico nacional é oficialmente antiga no Brasil. Entretanto, só recentemente, a partir do entendimento que o patrimônio cultural também é composto de bens culturais de natureza imaterial, as diversas práticas e manifestações culturais passaram a integrar o Patrimônio Cultural do Brasil. Neste artigo, sob a luz da noção de historicidade, buscamos sublinhar os principais marcos da política federal referentes ao patrimônio imaterial, o seu momento de construção e os atores envolvidos nesse processo. Não se ofuscando pela neblina que o discurso de uma antiga ancestralidade da política do patrimônio imaterial acarreta, sobretudo ao irmaná-la às ideias e ações de Mário de Andrade, objetivamos identificar os aspectos centrais da recente política, aspectos que a tornam sem precedente na trajetória das ações de preservação do patrimônio cultural no Brasil.

\section{PALAVRAS-CHAVE}

Historicidade. Patrimônio imaterial. Práticas sociais.

\footnotetext{
1. Parte deste artigo foi originalmente desenvolvido na minha dissertação de Mestrado: Patrimônio cultural e garantia de direitos intelectuais indígenas: construção de sentido a partir da experiência Huni kuin, Iphan, 2014.
} 


\section{HISTORICITY AND CORE ASPECTS OF THE FEDERAL POLICY FOR INTANGIBLE CULTURAL HERITAGE: AN INTERPRETATION}

\section{LEANDRO RIBEIRO DO AMARAL}

Instituto do Patrimônio Histórico e Artístico Nacional (Iphan), Rio Branco, Acre, Brasil

DOI: http://dx.doi.org.br/10.11606/issn.1980-4466.v0i19p8-32

\section{ABSTRACT}

The practice of valuation and preservation of representative assets of historical and artistic heritage is officially long running in Brazil. However, several practices and cultural events became part of the cultural heritage of Brazil only recently, when the understanding that cultural heritage also consists of intangible cultural assets began. In this article, under the light of the historicity concept, we seek to highlight the major milestones of the federal policy for intangible heritage, its time of construction and the agents involved in this process. Not becoming overshadowed by the fog inherent to the speech of an ancient ancestry of intangible heritage policy, especially when combined with the ideas and actions of Mario de Andrade, we aim to identify the key aspects of the recent policy, those that make it unprecedented in the history of cultural heritage conservation actions in Brazil.

\section{KEYWORDS}

Historicity. Intangible heritage. Social practices. 


\section{INTRODUÇÃO}

A prática de valoração, seleção e preservação de coisas representativas do patrimônio histórico e artístico nacional foi oficialmente instituída no Brasil no ano de 1937, com a criação do Serviço (hoje, Instituto) do Patrimônio Histórico e Artístico Nacional (Sphan [Iphan]) ${ }^{2}$. No mesmo ano, foi criado o Decreto-lei $\mathrm{n}^{\mathrm{o}} 25$, de 30 de novembro de 1937, também conhecido como lei do tombamento, instrumento jurídico que organizou a proteção do patrimônio histórico e artístico nacional e forneceu as bases legais para a preservação desses bens - móveis e imóveis.

Só a partir do ano 2000 as ações de consagração do patrimônio cultural em âmbito federal, a partir da introdução da noção de patrimônio imaterial, passaram a trabalhar de forma consistente e legal com a diversidade de grupos que compõem a sociedade brasileira, reconhecendo e valorizando suas práticas e manifestações culturais como patrimônio cultural do Brasil. O instrumento legal que norteia a política do patrimônio cultural imaterial é o Decreto $\mathrm{n}^{-}$3.551, de 4 de agosto de 2000. Este decreto presidencial instituiu a figura do registro de bens culturais de natureza

2. Criado em caráter experimental no ano de 1936, o Serviço do Patrimônio Histórico e Artístico Nacional (Sphan) foi legalmente institucionalizado no ano seguinte, por meio da Lei no 378, de 13 de janeiro de 1937, legislação esta que deu nova organização ao então Ministério da Educação e Saúdo Pública (MES) do Governo Getúlio Vargas. Para tanto, ver: MEC/SPHAN/PRÓ-MEMÓRIA,1980. 
imaterial, criou o Programa Nacional do Patrimônio Imaterial (PNPI) e deu outras providências sobre a matéria. Se comparada, portanto, com a longa trajetória da política federal levada a cabo pelo Iphan, verifica-se que as ações do patrimônio imaterial constituem uma prática recente e ainda - por que não? - em construção, o que torna oportuno o desenvolvimento de estudos que reflitam sobre os limites e possibilidades das suas ações e propostas.

Embora tardio, o decreto federal que regulamentou o instituto do registro de bens culturais de natureza imaterial tem sua fundamentação jurídica na Constituição Federal de 1988. Em seu artigo 216, caput, preceitua a Constituição Federal:

Constituem patrimônio cultural brasileiro os bens de natureza material e imaterial, tomados individualmente ou em conjunto, portadores de referência à identidade, à ação, à memória dos diferentes grupos formadores da sociedade brasileira, nos quais se incluem [...] [segue uma listagem tipológica de bens]. (BRASIL, 1988, grifos nossos)

Embora exista certo consenso nos discursos sobre o patrimônio imaterial brasileiro em defender uma ancestralidade para o tema que remonta a década de $1930^{3}$, é na Constituição de 1988 que está, segundo os resultados desta pesquisa, a gênese de que o patrimônio cultural brasileiro também é composto por bens culturais de natureza imaterial. Nenhum texto até então fez uso do adjetivo "imaterial" para se referir ao patrimônio cultural brasileiro. Não obstante, no plano internacional, o reconhecimento e a valorização de bens culturais marginalizados pelas políticas oficiais na área estão atrelados a reivindicações lançadas por diversos países em meados da década de 1970, que levaram a Organização das Nações Unidas para a Educação, a Ciência e a Cultura (Unesco) a considerar e investir em estudos que subsidiassem a construção de instrumentos adequados para

3. Colocada quase como um mito de origem, a vinculação da política de patrimônio imaterial com ações que remontam à década de 1930, principalmente as realizadas por Mário de Andrade nas suas viagens de (re)descobrimento do Brasil e outros folcloristas da época e posteriores, esteve fortemente presente nos estudos que subsidiaram a criação do Decreto no 3.551/20oo. Também está disseminada em estudos sobre o tema e em publicações do Iphan sobre a recente política. Para tanto, ver: IPHAN, 2000; 2010; FONSECA, 2005; SILVA, 2002. 
o tratamento desses bens ${ }^{4}$.

Outro preceito importantíssimo do artigo 216 da Constituição Federal vigente é o reconhecimento do valor de referência do patrimônio cultural (material ou imaterial) para os grupos detentores ou criadores desses bens. Confrontando a passagem da Constituição em comento com o que determina o Decreto-lei n⿳0 25/1937, segundo o qual a valoração do patrimônio histórico e artístico se justificava pelo "interesse público”, Ulpiano Toledo Bezerra de Meneses (2012) argumenta que o reconhecimento do valor referencial pela atual Carta Magna representa uma mudança paradigmática para o campo do patrimônio cultural brasileiro. Ao reconhecer que o patrimônio é portador de referência dos diferentes grupos formadores da sociedade brasileira, houve um "deslocamento da matriz" atribuidora de valor do Estado para a sociedade, argumenta o autor (MENESES, 2012, p. 33). Dessa forma, em tese, ainda segundo Meneses, o Poder Público passa a ter um "papel declaratório", e não mais constituidor de valor patrimonial, competindo-lhe a "proteção" desses bens com a colaboração da "comunidade". Em suma, com base no que determina a Constituição Federal vigente, entende-se que qualquer critério de seleção, mas principalmente de exclusão, que não seja respaldado pelos critérios dos próprios grupos detentores é ato que contraria a norma constitucional. Este preceito da Constituição Federal de 1988 é sem precedente na trajetória da preservação do patrimônio cultural no Brasil.

Aprofundando a discussão sobre a política federal do patrimônio imaterial, gostaríamos de compartilhar uma reflexão da antropóloga Manuela Carneiro da Cunha sobre essa política, pois ela nos foi de grande valia para despertar um olhar crítico em relação a essa nova área de atuação no campo do patrimônio cultural. Segundo a autora:

Políticas são objetos que, como os outros, se manifestam a um tempo como práticas e como representações. A "política do patrimônio imaterial" é ela própria, simultaneamente, um ser material e imaterial, e ambas as dimensões devem ser abordadas.

4. A referência aqui é sobre a insurgência de alguns países, liderados pela Bolívia, ao caráter restritivo da Convenção Relativa à Proteção do Patrimônio Mundial, Cultural e Natural aprovada pela Unesco no ano de 1972. Esta discussão será realizada adiante. 
Enquanto sua materialidade se manifesta nas práticas que enseja, e nos efeitos dessas práticas, sua imaterialidade é ligada a histórias e práticas particulares, que se incrustam no conceito e sobrecarregam-no com suas conotações. Essa sedimentação, que faz aparecer como evidente e inelutável o que é na realidade uma construção histórica, impõe limites à imaginação institucional. (CUNHA, 2005, p. 18, grifos nossos)

Considerando o exposto na citação acima, na busca de desnaturalizar a política federal do patrimônio imaterial e, de tal modo, apreendermos o que lhe é central, faz-se necessário um olhar focado na historicidade das ações que resultaram na instituição do Decreto $n^{\circ}{ }^{0} 3.551 / 2000$, pois este é o marco que regulamentou e implementou o preceito constitucional. Da mesma forma, não se pode perder de vista as pessoas que atuaram diretamente na construção desse instrumento de consagração do patrimônio cultural imaterial brasileiro. Ainda que tantos outros adjetivos sejam empregados para se referir a esses (novos) bens culturais (ou grupos sociais detentores), no caso brasileiro, também é preciso se ater ao adjetivo "imaterial", pois as palavras, enquanto construção de sentido intencional, não surgem ou nem são empregadas de forma despretensiosa. Complementarmente, atentar-se para os bens imateriais patrimonializados até então será de grande valia para o entendimento dos aspectos centrais da recente política patrimonial.

\section{CONSTRUÇÃO DA POLÍTICA FEDERAL DO PATRIMÔNIO CULTURAL IMATERIAL}

A promulgação do Decreto $\mathrm{n}^{\mathrm{0}} 3.551 / 2000$ foi precedida por uma percepção social sobre o tema historicamente construída. Ou seja, o decreto em comento, assim como a política cultural por ele instituída, foi fruto de mais de dois anos praticamente ininterruptos de trabalho, dos quais participaram e contribuíram inúmeras instituições, públicas e privadas, e uma gama considerável de colaboradores com reconhecido domínio sobre o tema.

Oficialmente, os trabalhos que subsidiaram a criação do Decreto $\mathrm{n}^{\mathrm{o}}$ 3.551/200o tiveram como marco a instituição, por meio de Portaria do 
Ministério da Cultura, no ano de 1998, da Comissão Patrimônio Imaterial5, doravante Comissão, "com a finalidade de definir propostas visando ao estabelecimento de critérios, normas e formas de acautelamento do patrimônio imaterial brasileiro"6. Para assessorar a Comissão, a mesma Portaria Ministerial criou o Grupo de Trabalho Patrimônio Imaterial (GTPI)7.

Antes, porém, outro marco nessa conjuntura específica foi o seminário "Patrimônio imaterial: estratégias e formas de proteção", também conhecido como "Seminário de Fortaleza". Promovido pelo Iphan e realizado na cidade de Fortaleza em 1997. Esse seminário, do qual resultou o documento "Carta de Fortaleza", reacendeu junto ao Poder Público a necessidade de regulamentar o preceito constitucional sobre patrimônio imaterial. Não por menos, no início do ano seguinte, ocorreu a criação da Comissão e do GTPI, e, a partir dos seus trabalhos, a promulgação do decreto presidencial que regulamentou o registro de bens culturais de natureza imaterial.

Ainda que, como já observamos, a gênese da noção de bens culturais de natureza imaterial esteja, no Brasil, na Constituição Federal de 1988, não se pode desconsiderar as contribuições do plano internacional para a matéria. Nesse sentido, de acordo com Márcia Sant'Anna (2001, p. 152), coordenadora do GTPI, a expansão da noção de patrimônio, acrescida de novas categorias que ultrapassavam a dimensão material desses bens, e que davam ênfase aos "processos e práticas culturais" entrou em cena no mundo ocidental "pela mão de asiáticos e de países do terceiro mundo". Para a autora, "a noção de patrimônio imaterial ou intangível começa a penetrar no discurso ocidental de patrimônio por meio das

5. Integraram a Comissão as seguintes pessoas (entre parênteses menção à função que os membros da Comissão ocupavam à época): Joaquim de Arruda Falcão Neto (Secretário-geral da Fundação Roberto Marinho); Marcos Vinicios Vilaça (Ministro do Tribunal de Contas da União - TCU); Eduardo Mattos Portella (Presidente da Fundação Biblioteca Nacional); e Tomas Farkas (membro do Conselho Consultivo do Iphan).

6. Ministério da Cultura, Portaria no 37, de 4 de março de 1998, art. 10 (publicado no Diário Oficial da União, em 6 de março de 1998). Finalizado o prazo dessa portaria, outras foram criadas com o objetivo de dar continuidade aos trabalhos da Comissão e do GTPI. Para tanto, ver: IPHAN, 200o, p. 49-53.

7. Ao longo dos quase dois anos de trabalho, as seguintes pessoas integraram o GTPI, sob a coordenação da primeira (entre parênteses menção à instituição representada por elas): Márcia Genésia de Sant’Anna (Iphan); Célia Maria Corsino (Iphan); Maria Cecília Londres Fonseca (MinC); Ana Maria Lopes Roland (Iphan); Cláudia Márcia Ferreira (Funart); Ana Cláudia Lima e Alves (Iphan); Ana Gita de Oliveira (Iphan); e Sydney Sergio Fernandes Sollis (Iphan). Informações obtidas em IPHAN, 2000 e por meio de pesquisas na plataforma Lattes. 
criações populares, na primeira expansão tipológica do conceito ocorrida nos anos 60 ", contudo, sua assimilação pelo ocidente "só se verifica a partir dos anos 80" (SANT'ANNA, 2001, p. 153). Importa observar que os documentos internacionais que precedem a Constituição Federal brasileira de 1988 não empregam o adjetivo "imaterial" para se referir a esses bens culturais. "Cultura popular", "patrimônio vivo", "oral” são as expressões mais frequentes. Imaterial é, portanto, uma criação original do terreno brasileiro sobre o assunto.

\section{Aspectos centrais da política federal do patrimônio cultural imaterial}

Com o intuito de dar sentido à nossa narrativa, começaremos a discussão sobre a política cultural em pauta com a seguinte indagação: o que é patrimônio cultural imaterial, ou bens culturais de natureza imaterial?

De saída, é pertinente observar que a adjetivação "imaterial” tem uma intenção clara e deliberada de se contrapor à dimensão (ou privilégio) material de outros bens selecionados e declarados patrimônio cultural99. O que nos diz este contraponto?

Datado no tempo e muito bem delimitado no espaço, isto é, na Europa do final do século XVIII, sobretudo na França, as ações de seleção e preservação de coisas declaradas patrimônio nacional estiveram restritas aos bens monumentais, bem como, e pela noção sublinhada anteriormente, a uma representação oficial e elitista da nação (CHOAY, 2006). No Brasil, por longas décadas, o tratamento da matéria pelo Estado não foi diferente. "Bens móveis e imóveis", representativos de "fatos memoráveis" ou de "excepcional valor": eis as principais definições contidas no instrumento jurídico que por mais de 60 anos fundamentou, isoladamente, a seleção do patrimônio

8. Nesta passagem, acreditamos que a autora esteja se referindo à "Carta de Veneza", de 1964. Concebida sob os auspícios do Conselho Internacional dos Monumentos e Sítios (ICOMUS), a Carta, em seu artigo 1o considera que a noção de monumento histórico também deve incluir "as obras modestas, que tenham adquirido, ao longo do tempo, uma significação cultural" (IPHAN, 2004, p. 91-95).

9. Fato consumado e ricamente explorado pela bibliografia especializada sobre o tema, a trajetória da preservação do patrimônio histórico e artístico nacional concentrou-se, até a instituição da política do patrimônio imaterial, na valoração de bens culturais arquitetônicos, mormente àqueles referentes ao barroco colonial, posteriormente taxados, com certa ironia, de patrimônio pedra e cal. Para tanto, ver: GONÇALVES, 2002; FONSECA, 2000; 2005; CHUVA, 2009. 
histórico e artístico nacional brasileiro, isto é: o Decreto-lei noํㅡㄴ 25/1937. Dessa forma, é em contraponto a essa ênfase em certos bens de representação socialmente restrita que se forja, e se adota, mais recentemente, a noção de que existe um patrimônio imaterial, em grande medida constituído por bens culturais representativos de segmentos excluídos da ação patrimonial oficial até então (FONSECA, 2001; 2005; SANT’ANNA, 2001).

Assim, do exposto até aqui é possível chegar à seguinte aferição: inclusão de bens culturais marginalizados; criações populares, dinâmicas e processuais - estas são algumas características atribuídas ao patrimônio imaterial que gostaríamos de sublinhar neste momento.

Vimos que a Constituição Federal de 1988 é, no Brasil, o primeiro documento a empregar a noção de patrimônio cultural imaterial. Não obstante a importância da determinação constitucional sobre a matéria, não há na Constituição uma definição mínima sobre o que sejam esses bens culturais de natureza imaterial. O que há, no entanto, é a especificação tipológica de bens culturais passíveis de patrimonialização. Os incisos I e II do artigo 216, por exemplo, mencionam, respectivamente, as "formas de expressão" e "os modos de criar, fazer e viver". Daí apreende-se pouca coisa, pois, assim como uma língua ou uma dança são formas de expressão, um edifício feito sob determinado estilo arquitetônico também não o é? Para concluirmos esta parte, é importante ressaltar que as categorias ou tipologias da Constituição foram recepcionadas, como é sabido, pelo decreto que regulamentou a política do patrimônio imaterial no Brasil.

Também o Decreto $\mathrm{n}^{\mathrm{o}}$ 3.551/200o não traz no corpo do seu texto uma conceituação sobre bens culturais imateriais ou patrimônio imaterial. Assim, é preciso recorrer à exposição de motivos desenvolvida no Relatório Final das atividades da Comissão e do GTPI para apreendermos o entendimento dos formuladores da política sobre a noção de patrimônio imaterial.

Contudo, importa observar que durante muito tempo os elaboradores do decreto cogitaram inserir no texto do instrumento legal uma conceituação sobre bens culturais imateriais. Para dar uma ideia, das oito propostas de documento legal formuladas durante os trabalhos da Comissão e do GTPI que tomamos conhecimento, até a sétima versão (6 $6^{\mathrm{a}}$ Minuta de Decreto) havia uma conceituação inserida no texto do documento. No entanto, segundo constatamos na documentação pesquisada, ela foi excluída com a 
intenção de deixar o texto do documento legal mais enxuto. No documento referido a proposta de conceituação do tema se deu da seguinte forma:

Entende-se por bens culturais de natureza imaterial as criações culturais de caráter dinâmico e processual (saberes, modos de fazer, festas, celebrações, folguedos, linguagens verbais, musicais, performáticas e iconográficas, conjuntos de práticas culturais coletivas, concentradas em determinados espaços), fundadas na tradição e manifestadas por indivíduos ou grupos de indivíduos como expressão de sua identidade cultural e social.

Para os efeitos desse Decreto toma-se tradição no seu sentido etimológico de "dizer através do tempo", significando práticas produtivas, rituais e simbólicas que são constantemente reiteradas, mantendo, para o grupo, um vínculo do presente com o passado ${ }^{10}$.

Não aprofundaremos a análise do trecho citado, pois isso será feito ao discutirmos o documento Relatório Final das atividades da Comissão e do GTPI, que, em grande medida, trabalhou com o mesmo sentido da citação acima. Por fim, gostaríamos de advertir que a conceituação citada, embora não tenha sido inserida no texto do Decreto nº 3.551/200o, foi reproduzida, com exceção das exemplificações de bens, na Resolução n⿳o oo1, de 3 de agosto de 2006, documento instituído pelo Iphan e que regulamentou os procedimentos a serem observados na instauração e instrução do processo administrativo de Registro de Bens Culturais de Natureza Imaterial.

Não é preciso um estudo muito aprofundado sobre os trabalhos da Comissão e do GTPI para constatar que a noção de patrimônio imaterial que eles ajudaram a formular e disseminar está intrinsecamente ligada à ideia de cultura popular. Termo problemático por sua excessiva generalização, é difícil se desvincular dele quando se trata do patrimônio imaterial. Essa relação tem sido inevitável por vários motivos.

10. Disponível em: Arquivo Central do Iphan, Seção Brasília. Unidade Produtora: Departamento de Identificação (DID). Descrição: "Documentos do GTPI", caixa "C". Célula: Minuta de Decreto, $\sigma^{a}$ versão (Observação: as próximas referências às fontes desta documentação serão feitas de forma mais abreviada). 
Primeiro porque, nos trabalhos da Comissão e do GTPI, buscou-se irmanar a preocupação brasileira sobre o patrimônio imaterial com as recomendações internacionais formuladas pela Unesco, e, explicitamente, as recomendações acionadas ${ }^{11}$ se fundam no tratamento daquilo que a organização internacional, de forma genérica e homogeneizadora, chama de cultura tradicional e popular (IPHAN, 2000, p. 11) ${ }^{12}$.

Segundo porque, no plano interno, buscaram fundamentar e legitimar a noção de patrimônio imaterial a partir da trajetória brasileira no trato das “expressões populares", resgatando projetos e ações de Mário de Andrade nos idos dos anos 1930 sobre a matéria, do Centro Nacional de Referência Cultural (CNRC) na década de 1970, e também nas ações do Centro Nacional de Folclore e Cultura Popular, ou mesmo da Comissão Nacional do Folclore, criada em 1947 (IPHAN, 200o, p. 11). No próprio Relatório Final da Comissão e do GTPI está explícito que os projetos e ações tomados como referência sobre o assunto eram voltados para as culturas tradicionais e populares. Embora não haja no Relatório Final esforço mínimo para discorrer sobre o que vem a ser cultura tradicional e popular, reconhecem-se os limites e problemas dessa noção, mas nem por isso conseguem desvincular a noção de patrimônio imaterial da ideia de expressões tradicionais e populares.

Não discordamos que Mário de Andrade e outros tantos folcloristas e instituições que trataram da cultura popular e do folclore valorizaram muitas manifestações culturais de grupos sociais atualmente alvos da política federal do patrimônio imaterial. Entretanto, a forma de atuação e os objetivos dos trabalhos são, segundo entendemos, muito diferentes. Essa diferença é crucial para a apreensão dos aspectos centrais da política do patrimônio imaterial que se concretizou.

Quando se argumenta em prol de uma genealogia para o patrimônio

11. Dentre outros, um dos textos internacionais que guiou os trabalhos do GTPI foi a Recomendação para a Salvaguarda da Cultura Tradicional e Popular, de 1989, da Unesco. O título do documento já é elucidativo da relação construída entre o patrimônio não consagrado (até então) e a ideia de cultura tradicional e popular. Há várias menções a essa Recomendação durante os trabalhos da Comissão e do GTPI. A cópia do texto, aliás, está arquivada com outros documentos gerados durante os trabalhos que antecederam a promulgação do Decreto no 3.551/200o. É importante observar também que a Recomendação da Unesco é posterior à Constituição Federal de 1988. 12. As argumentações aqui estão fundamentadas no documento "Relatório Final das Atividades da Comissão e do Grupo de Trabalho Patrimônio Imaterial”, publicado em IPHAN, 200o, p. 11-17. 
imaterial nas ideias e ações de Mário de Andrade, os autores ${ }^{13}$ desse discurso fazem referência ao seu anteprojeto para "[...] a organização dum serviço de fixação e defesa do patrimônio artístico nacional", elaborado no ano de 1936 a pedido de Gustavo Capanema, então Ministro da Educação e Saúde Pública (MES) (Mário de Andrade apud IPHAN, 2002, p. 271) ${ }^{14}$. Conquanto no anteprojeto exista, inegavelmente, uma visão mais ampla dos bens passíveis de patrimonialização do que a consagrada pelo Serviço criado em 1937, sugerindo, por exemplo, as categorias "arte ameríndia" e "arte popular", o que se apreende no texto do referido documento é uma concepção muito diferente da adotada pela atual política do patrimônio imaterial. Pois, rapidamente, enquanto a ênfase das ações de salvaguarda empreendidas pela política do patrimônio imaterial recai, sobretudo, no processo que possibilita a existência de determinado bem, isto é, no conhecimento, no saber fazer ou executar, daí a adjetivação imaterial, a proposta de Mário de Andrade centrava-se muito mais nos objetos, no artefato, ou seja, no produto e não na produção. A perspectiva de preservação da arte popular e arte ameríndia proposta por Mário de Andrade era muito mais arquivista e museográfica do que as ações hoje implementadas pela política de patrimônio imaterial, que buscam fortalecer as condições de existência de determinada prática ou manifestação cultural ${ }^{15}$.

Por exemplo, ao especificar quais bens comporiam a categoria "arte popular”, expôs Mário de Andrade no seu anteprojeto: “a) Objetos - Fetiches, cerâmica em geral, indumentária, etc. b) Monumentos - Arquitetura popular, cruzeiros, capelas e cruzeiros mortuários de beira-estrada, jardins, etc. [...]" (ANDRADE apud IPHAN, 2002, p. 274). Da mesma forma, em relação à "arte ameríndia", agrupada pelo autor com a "arte arqueológica", o que, de saída, torna-se um dado revelador para a argumentação que

13. A título de exemplo, ver nota número 3.

14. Trecho da carta de Mário de Andrade para Gustavo Capanema, encaminhando sugestões do anteprojeto para a criação do órgão público. Trata-se de uma reprodução do documento original publicada com o anteprojeto na Revista do Patrimônio Histórico e Artístico Nacional, no 30, p. 271-287, 2002.

15. O apoio às condições de existência do dito patrimônio cultural imaterial é um ponto chave do Programa Nacional do Patrimônio Imaterial (PNPI). São ações implementadas a partir do que se convencionou chamar de Planos de Salvaguarda. Para saber mais, consulte a página do PNPI. Disponível em: <http://portal.iphan.gov.br/portal/baixaFcdAnexo.do?id=201>. Acesso em: 1 mar. 2015. 
estamos tecendo, sugeriu o autor de "Macunaíma”: "a) Objetos - Fetiches; instrumentos de caça, de pesca, de agricultura; objetos de usos domésticos; veículos, indumentárias, etc. etc. [...]" (ANDRADE apud IPHAN, 2002, p. 274). Ainda que no quarto item de sugestões de cada uma das categorias aqui citadas Mário de Andrade tenha mencionado o "Folclore - Música popular, contos, histórias, lendas, superstições [...] etc." - o que tem merecido a atenção das ações do patrimônio imaterial -, a ideia de preservação era bem diferente das ações atuais. Um olhar direcionado para os trabalhos realizados por Mário de Andrade nas suas “"viagens de (re)descobrimento do Brasil" nos idos da década de 1920, e posteriormente enquanto Chefe do Departamento de Cultura de São Paulo, constatará que suas ações sobre esses bens ou inventários foram marcadas pelos registros fotográfico, audiovisual e etnográfico (NOGUEIRA, 2007), ou seja, um trabalho arquivista e conceitualmente diferente do que é central na atual política do patrimônio imaterial.

É impossível não reconhecer a importância dos trabalhos e contribuições de Mário de Andrade no processo de construção da identidade nacional brasileira a partir da seleção, consagração e preservação de determinados bens culturais. Sobretudo no que diz respeito a uma visão não monumentalista dos bens passíveis de patrimonialização, o que se atesta nas categorias de arte ameríndia e arte popular do seu anteprojeto (SILVA, 2002). Contudo, canonizá-lo como "santo padroeiro"16 da atual política de patrimônio imaterial é lançá-lo em uma neblina que pouco contribui para o entendimento e apreensão do que é central, negligenciando a sua historicidade e o papel dos verdadeiros atores envolvidos na sua efetiva construção e posterior execução ${ }^{17}$, que, inevitavelmente, deixaram suas

16. Em uma publicação que visou divulgar os princípios, ações e resultados da política do patrimônio cultural imaterial no Brasil (2003-2010), intitulada Os sambas, as rodas, os bumbas, os meus e os bois, encontra-se o seguinte discurso: "Se, por ocasião, a reflexão e a consequente ação sobre o patrimônio cultural imaterial do Brasil tivessem um santo padroeiro, esse santo seria Mário de Andrade" (IPHAN, 2010, p. 11).

17. Integrantes do Grupo de Trabalho Patrimônio Imaterial (GTPI) posteriormente assumiram cargos de chefia na coordenação da política federal do patrimônio imaterial. A saber: Márcia Sant'Anna, que exerceu a função de coordenadora do GTPI foi a primeira Diretora do Departamento de Patrimônio Imaterial (DPI/Iphan), cargo hoje ocupado por Célia Maria Corsino, também integrante do GTPI. Maria Cecília Londres Fonseca e Ana Gita de Oliveira são, respectivamente, Conselheira da Câmara Temática do Patrimônio Imaterial e Coordenadora-geral de Identificação e Registro do DPI/Iphan. Informações obtidas na plataforma Lattes e na página do Iphan na web. 
marcas incrustadas na política pública.

Expressando claramente a dificuldade de elaborar um conceito que abrangesse dos bens culturais de natureza imaterial e reconhecendo os aspectos um tanto vagos das definições tentadas até então, assim foi registrado no referido Relatório Final:

[...] não há um consenso, no plano internacional ou nacional, sobre que expressão melhor define o conjunto desses bens culturais. [...] Verifica-se que várias expressões, todas igualmente problemáticas e simplificadoras do ponto de vista conceitual, têm sido utilizadas, sendo as mais consagradas "patrimônio intangível", "patrimônio imaterial", "cultura tradicional e popular" e, mais recentemente, "patrimônio oral". (IPHAN, 200o, p. 12-13)

Por conseguinte, argumenta-se: se o emprego dos adjetivos "imaterial" ou "intangível" busca se contrapor ao patrimônio material, enfatizando que nesses casos importa mais o conhecimento e o processo que possibilita a existência de determinada prática ou expressão, peca por desconsiderar os resultados desses bens e suas condições materiais de existência. Já o adjetivo "oral" enfatiza a forma de transmissão dos conhecimentos relativos a esses bens, contudo, nem sempre dá conta de toda a complexidade que os envolve, e, por outro lado, busca superar os limites conceituais contidos nas expressões "tradicional" e "popular", que, muitas vezes, por força de certos equívocos reducionistas conduzem a entendimentos restritos sobre esses bens, "vinculando-os a critérios rígidos de temporalidade, classe e autenticidades" (IPHAN, 2000, p. 13).

Cientes dos problemas e limites das expressões empregadas nas tentativas de conceituação desse repertório de bens, a Comissão e o GTPI optaram por fazer valer o artigo 216 da Constituição Federal, que preceituou o patrimônio cultural brasileiro como sendo os bens de natureza material e imaterial, portadores de referência à identidade, à ação e à memória dos diferentes grupos formadores da sociedade brasileira. Todavia, fazem a seguinte observação:

Não há dúvida de que as expressões "patrimônio imaterial" e "bem cultural de natureza imaterial" reforçam uma falsa 
dicotomia entre esses bens culturais vivos e o chamado patrimônio material. Por outro lado, contudo, com essa distinção, delimita-se um conjunto de bens culturais que, apesar de estar intrinsecamente vinculado a uma cultura material, não tem sido reconhecido oficialmente como patrimônio nacional. (IPHAN, 2000, p. 13)

Importa observar que os próprios formuladores do instrumento jurídico que regulamentou as ações sobre o patrimônio imaterial reconhecem que tratar o patrimônio a partir de terminologias como material ou imaterial constitui-se em uma "falsa dicotomia" (IPHAN, 2000, p. 13). Portanto, mais uma estratégia de inclusão e menos um conceito, o adjetivo imaterial busca incluir no campo do patrimônio cultural "nacional" uma série de bens (e grupos) que não eram tratados pelas ações específicas do Poder Público como tais.

É preciso uma breve consideração sobre o grau de entendimento expresso no documento elaborado pela Comissão e pelo GTPI. A pesquisa que realizamos no Arquivo Central do Iphan, Seção Brasília, sobre a documentação gerada e acumulada pelos trabalhos do GTPI nos revelou que a política federal do patrimônio imaterial foi construída por muitas mãos, muito além das pessoas que integraram a Comissão e o GTPI. Apesar disso, os estudos sobre o tema praticamente não abordaram de forma qualificada essas contribuições, que acabam, assim, negligenciadas.

Sobre os limites dos adjetivos "imaterial" ou "popular" para se referir aos bens culturais que a política federal do patrimônio "imaterial" busca abarcar, existe um documento no arquivo referido que possibilita, de forma exemplar, resgatar essas contribuições anônimas que, possivelmente, levaram a Comissão e o GTPI a chegarem a certos entendimentos. Trata-se de uma carta assinada por Ulpiano Bezerra Toledo de Menezes, datada de 14 de novembro de 1997, e enviada a Márcia Sant'Anna ${ }^{18}$. Na correspondência, Meneses expressa algumas das suas impressões sobre as discussões travadas no Seminário de Fortaleza. Importa ressaltar que, nessa época, o GTPI,

18. Disponível em: Arquivo Central do IPHAN, Seção Brasília. DID, "Documento do GTPI" caixa, "C" / Correspondências recebidas / Memorandos / Remetente: Ulpiano B. T. de Meneses. 
coordenado por Márcia Sant'Anna, ainda não havia sido constituído. Mas, sendo ela uma das idealizadoras do seminário, isso justifica o destinatário da correspondência.

No documento, Meneses afirma que a dicotomia patrimônio material/ imaterial definitivamente já entrou em cena no nosso vocabulário, pois já está em voga no vocabulário internacional, sobretudo por ação da Unesco. A partir daí, considerando a necessidade de entender a referida organização internacional de forma crítica, faz a seguinte colocação:

[...] podemos até receber e aceitar terminologias como "patrimônio imaterial” mas com visão crítica. Se eu já estava convencido antes, reforcei a convicção de que falar de patrimônio imaterial é agravar a fetichização que sempre imperou em nosso campo, que ignora que nele, só há bens simbólicos. (grifos do autor)

O que se afere da colocação de Meneses é a falta de sustentação da dicotomia patrimônio material/imaterial, como se os bens imateriais fossem constituídos por bens simbólicos e os de natureza material não. Com esse grau de entendimento, sendo o campo do patrimônio cultural um lugar de valoração, todos os patrimônios - uma igreja ou uma festa - são bens simbólicos. Mas a ressalva sobre a necessidade de se encarar o emprego dessas terminologias com "visão crítica", e não como "mera questão semântica", segundo afirma Meneses ter ouvido no Seminário de Fortaleza, encontra ressonância nas ressalvas que a Comissão e o GTPI fazem na exposição de motivos ao usar o termo patrimônio imaterial.

A segunda impressão que Meneses afirma ter tido no Seminário de Fortaleza foi a "folclorização do patrimônio". Com uma crítica severa, escreve Ulpiano Toledo Bezerra de Meneses:

Nos três dias em que participei do Seminário, tive a oportunidade de ver e ouvir muita coisa emocionante e relevante como experiência. No entanto, não posso deixar de apontar a total ausência de espírito crítico, isto é, de esforço analítico - como se os valores fossem autoexplícitos, como se tudo estivesse já para sempre resolvido e óbvio. Por isso, cheguei até a imaginar, em certos momentos, que estivéssemos voltando 
décadas atrás, com as devidas mudanças inevitáveis, a experiências próximas dos Centros Populares de Cultura. Fiquei impressionado com a desmobilização como característica desse patrimônio, seu congelamento, sua a-historicidade, sua essencialidade ilusória, seu caráter quase de compensação apaziguadora. Eu senti muito de etnocentrismo paternalista [...]. (grifo do autor)

Em parte, é possível identificar a recepção da crítica que Meneses faz sobre a forma como se iniciaram as discussões que culminaram na regulamentação do Registro do patrimônio imaterial quando a Comissão e o GTPI reconhecem a "falsa dicotomia" material/imaterial; quando ressaltam os limites das expressões empregadas até então na tentativa de conceituar esses bens. Contudo, acreditamos que muitas das críticas colocadas por Meneses ainda precisam ser consideradas, tanto pela política do patrimônio imaterial quanto pelos estudos que se dedicam a ela. Pois é facilmente observável a falta de historicidade, até mesmo de anacronismo, quando lemos que a política do patrimônio imaterial tem sua ancestralidade em Mário de Andrade. Como desdobramento do anacronismo exposto anteriormente, sentimos também haver "desmobilização" e "essencialidade ilusória" quando o reconhecimento da importância do patrimônio cultural de grupos historicamente excluídos pela política oficial é colocado como atualização intrínseca do olhar do Estado e de seus agentes, desconsiderando os processos de mobilização e luta desses próprios grupos e seus parceiros na conquista dos seus direitos.

Ulpiano Toledo Bezerra de Meneses finaliza suas considerações à futura coordenadora do GTPI com algumas sugestões, dentre as quais:

[...] reconhecer no patrimônio intangível uma diversidade e uma complexidade que jamais permitirão falar-se dele unitariamente;

[...] reconhecer que tal diversidade implica não apenas ambiguidade, como foi oportunamente lembrado, mas também, e com muitíssima frequência, conflito. A mera diversidade não basta: ela normalmente se organiza em hierarquias;

[...] Nessa diversidade, há que se dar um lugar relevante à 
cultura popular, mas não há a menor justificativa em fazer coincidir com ela, reducionisticamente, o domínio do patrimônio intangível;

[...] Há absoluta necessidade de contextualização desse patrimônio [...].

Algumas questões levantadas por Meneses urgem por reflexões, mas não caberá, por motivos técnicos, a este artigo discuti-las. A organização hierárquica da diversidade cultural, no caso, do patrimônio cultural, tema que possui ricas sugestões em Nestor Canclini (1994), mas também os conflitos, mormente àqueles surgidos com a implementação das políticas de patrimônio cultural são, sem dúvida, questões relevantes e necessárias para a qualificação da bibliografia sobre a área. Por outro lado, a falta de historicidade, de espírito crítico, bem como os problemas da relação entre patrimônio imaterial e cultura popular não passaram despercebidos neste trabalho.

Nossa intenção em trazer à tona a correspondência de Meneses é evidenciar o quando a política do patrimônio imaterial foi (e é) fruto de uma construção histórica muito bem circunscrita. Indo um pouco além, mostrar a importância de se dar voz às pessoas que contribuíram para a sua construção. Com essa pretensão, desnaturalizando a política do patrimônio imaterial, buscamos conduzi-la para o lugar que lhe é próprio: o campo das práticas sociais.

À medida que ainda não há um conceito que dê conta desse campo de atuação do patrimônio cultural, para se apreender o que tem sido alvo dessa política é necessário se ater às especificações tipológicas e às categorias criadas para dar conta desse universo de bens culturais. No Decreto $\mathrm{n}^{-}$ 3.551/200o, essas categorias e tipologias estão expressas nos quatro livros criados para a inscrição dos bens culturais patrimonializados, a saber: Livros de Registro dos Saberes, das Celebrações, das Formas de Expressão e dos Lugares.

Para cada um dos livros são dados exemplos de bens culturais passíveis de Registro. Assim, no Livro dos Saberes “[...] serão inscritos conhecimentos e modos de fazer enraizados no cotidiano das comunidades"; no Livro das Celebrações, “[...] rituais e festas que marcam a vivência coletiva 
do trabalho, da religiosidade, do entretenimento e de outras práticas da vida social”; em Formas de Expressão, “[...] as manifestações literárias, musicais, plásticas, cênicas e lúdicas; e, por fim, no Livro de Registro dos Lugares, “[...] serão inscritos mercados, feiras, santuários, praças, e demais espaços onde se concentram e reproduzem práticas culturais coletivas" (IPHAN, 2000, p. 25).

A partir das especificações preceituadas pelo Decreto $\mathrm{n}^{\mathrm{0}}$ 3.551/2000, verifica-se uma expressiva expansão dos bens passíveis de se tornarem patrimônio cultural brasileiro. Constata-se, pelo emprego de certos termos adotados (cotidiano, comunidades, religiosidade, práticas culturais coletivas), tratar-se de um olhar que entende esses bens como portadores de laços de sociabilidade e ligados às experiências cotidianas da vida social. Claramente, a monumentalidade não é requisito para a valoração e seleção desses bens culturais. Chega-se, assim, a uma concepção de patrimônio cultural muito mais abrangente que a consagração do patrimônio histórico e artístico majoritariamente realizada por mais de seis décadas na trajetória de atuação do Iphan.

Vejamos como se expressaram a Comissão e o GTPI em relação às categorias e tipologias contidas nos livros de registro:

Ao se delimitar o universo dos bens culturais imateriais por meio da indicação do conteúdo dos Livros de Registro, buscou-se evitar conceituações rígidas e apriorísticas, com a expectativa de que essa definição abrangente venha a estimular o processo de construção do conceito de patrimônio imaterial, mantidos os parâmetros estabelecidos pela Constituição. (IPHAN, 200o, p. 16)

Explicitamente diz-se que não há um conceito de patrimônio imaterial, mas trata-se de uma conceituação em aberto. O acúmulo da prática de patrimonialização dos bens culturais imateriais oferece uma contribuição notória para uma lapidação conceitual da matéria.

Importa ressaltar que na Resolução n⿳o 001/2006, o Iphan expôs o seu entendimento sobre a noção estruturadora da política do patrimônio imaterial da seguinte forma:

[...] se entende por bem cultural de natureza imaterial as 
criações culturais de caráter dinâmico e processual, fundadas na tradição e manifestadas por indivíduos ou grupos de indivíduos como expressão de sua identidade cultural e social; [...] para os efeitos desta Resolução, toma-se a tradição no seu sentido etimológico de "dizer através do tempo", significando práticas produtivas, rituais e simbólicas que são constantemente reiteradas, transformadas e atualizadas, mantendo, para o grupo, um vínculo do presente com o seu passado. (IPHAN, 2006, Preâmbulo) ${ }^{19}$

Na Resolução em comento há um esforço epistemológico no sentido de conceituar bens culturais de natureza imaterial inexistente nos outros documentos legais sobre o tema. Como se vê, o primeiro sentido atribuído a esses bens é o seu caráter dinâmico e processual. São criações culturais em movimento, abertas ao diálogo da inclusão/exclusão, isto é, são criações vivas, se quisermos usar outro adjetivo por vezes empregado no lugar de imaterial; e por serem processuais são atualizadas e transformadas constantemente. Porém, a relação com o tempo, como em qualquer patrimônio cultural, é outra característica definidora desses bens, sobretudo com o tempo passado; não um passado que as aprisione, e sim um passado que fornece o sentimento de pertencimento: trata-se dos "valores afetivos", para usarmos uma definição cunhada por Ulpiano Toledo Bezerra de Meneses (2012, p. 36). Por fim, como se nota, é a mesma conceituação que se pretendia inserir no texto do documento legal que regulamentou o registro do patrimônio imaterial presente na minuta de decreto citada anteriormente.

É importante advertir que em nenhum documento legal ou oficial sobre patrimônio imaterial aparece menção de que essa política é destinada a bens culturais de grupos determinados. Afirma-se, contudo, que são bens culturais fundados na tradição (Resolução no 001/2006), e o emprego dessa expressão pode dizer muita coisa, mas, logo em seguida, justifica-se o entendimento adotado de tradição com o intuito de se evitar interpretações que acusem a política do patrimônio imaterial de tradicionalismo mendação sobre a Salvaguarda da Cultura Tradicional e Popular, aprovada pela Unesco em 1989 e discutida no segundo capítulo deste trabalho. 
ou conservadorismo.

Outrossim, após esclarecer o sentido de tradição adotado pela política de patrimônio imaterial, foram expressadas no texto da Resolução no 001/2006 duas intenções da política de patrimônio imaterial que acreditamos ser centrais para o seu entendimento. Assim está:

[...] a instituição do Registro de Bens Culturais de Natureza Imaterial, além de contribuir para a continuidade dessas manifestações, abre novas e mais amplas possibilidades de reconhecimento da contribuição dos diversos grupos formadores da sociedade brasileira. (IPHAN, 2006, Preâmbulo, grifos nossos)

Ao ter por intenção contribuir para a continuidade dessas manifestações, francamente se reconhece que as condições necessárias para a existência desses bens (principalmente o conhecimento, o saber fazer...) estão vivas ou não se perderam completamente. E aqui reside outro aspecto importante da noção em discussão: o patrimônio imaterial é, sobretudo, uma prática ou manifestação cultural do/no presente.

Com base no que foi exposto, pode-se dizer que a perspectiva de patrimônio imaterial se desloca do objeto, do produto final de determinada prática ou manifestação para, um passo atrás, centrar-se no processo de produção, ou seja, no saber fazer ou executar determinado bem cultural. $\mathrm{O}$ central agora passa a ser o meio pelo qual o bem cultural existe e se transforma, e não tanto o seu fim, embora este também seja um aspecto importante para se apreender o bem cultural na sua totalidade. Esta é a principal especificidade da política do patrimônio imaterial. Contrapondo-a com a política do patrimônio material, chega-se ao seguinte resultado: enquanto as ações sobre o patrimônio material visam conservar o objeto patrimônio, preservando-o por inúmeros meios pelo tempo que for possível, as ações sobre o patrimônio imaterial visam "conservar" o conhecimento (imaterial) que possibilita a materialização de práticas e expressões culturais.

A segunda intenção da política, segundo a Resolução citada, é mais sintomática para o entendimento da noção de patrimônio imaterial: o intuito de trabalhar e valorizar a contribuição dos diversos grupos formadores 
da sociedade brasileira. Se olharmos para a trajetória da política federal de patrimônio cultural até aquela época, trata-se, deliberadamente, de uma intenção compensatória. Mas quem são esses grupos? Alguns exemplos podem elucidar a discussão.

Até o momento, a lista de bens culturais registrados disponível na página do Iphan na internet soma um total de 29 registros $^{20}$. Dentre eles, tem-se: seis bens culturais de povos indígenas ${ }^{21}$; seis bens culturais diretamente ligados a grupos de matriz afro-brasileira ${ }^{22}$; os outros bens registrados, majoritariamente, são representativos de grupos ou comunidades locais, relacionados a experiências coletivas do trabalho, da religiosidade e da sociabilidade ou entretenimento ${ }^{23}$.

Ou seja: povos indígenas e comunidades de matriz afro-brasileira representam quase metade dos bens culturais registrados até o momento. Daí confirma-se a intenção da política do patrimônio imaterial de ser uma ação compensatória, incluindo grupos, suas práticas e expressões culturais no panteão nacional do patrimônio cultural construído pelo Iphan. Trata-se de uma política afirmativa. Acreditamos que sua proposta inclusiva é mais importante para uma futura conceituação do patrimônio imaterial que a necessidade de um tratamento (gestão) diferenciado para esses bens, ainda que este tratamento diferenciado também seja importante.

\footnotetext{
20. Disponível em: $<$ http://portal.iphan.gov.br/portal/montarPaginaSecao.do?id=12456\&retorno =paginaIphan $>$. Acesso em: 30 out. 2014. Ressalta-se que essa lista já está desatualizada, mas que as informações são válidas para este contexto.

21. São eles: Arte Kusiwa - Pintura corporal e arte gráfica do povo Wajãpi, Amapá, inscrito no Livro das Formas de Expressão; Cachoeira de Iauaretê - Lugar sagrado dos povos indígenas dos rios Uapés e Papuris, alto rio Negro, Amazonas, inscrito no Livro dos Lugares; Ritual Yaokwa, do povo indígena Enawenawe, Mato Grosso, inscrito no Livro das Celebrações; Sistema Agrícola Tradicional dos povos indígenas do Rio Negro, Amazonas, inscrito no Livro dos Saberes; Saberes e práticas associados aos Modos de Fazer Bonecas Karajá, do povo Karajá, Tocantins, inscrito no Livro dos Saberes; e o Ritixòkò: expressão artística e cosmológica do povo Karajá, inscrito no Livro das Celebrações.

22. São eles: Samba de roda do Recôncavo Baiano, inscrito no Livro das Formas de Expressão; Ofício das Baianas de Acarajé, inscrito no Livro dos Saberes; Jongo no Sudeste, inscrito no Livro das Formas de Expressão; Matrizes do samba no Rio de Janeiro: partido-alto, samba de terreiro e samba-enredo, inscrito no Livro das Formas de Expressão; Roda de Capoeira, inscrito no Livro das Formas de Expressão; e Ofício do Mestre de Capoeira, inscrito no Livro dos Saberes.

23. Dentre eles: Ofício das paneleiras de Goiabeira, Espírito Santo, inscrito no Livro dos Saberes; Círio de Nossa Senhora de Nazaré, Pará, inscrito no Livro das Celebrações; Feira de Caruaru, Pernambuco, inscrito no Livro dos Lugares; Frevo, Pernambuco, inscrito no Livro das Celebrações; Modo artesanal de fazer Queijo de Minas, nas regiões do Serro e das serras da Canastra e do Salitre, inscrito no Livro dos Saberes; Modo de fazer Renda Irlandesa, Sergipe, inscrito no Livro dos Saberes etc.
} 
Em relação ao aspecto da necessidade de uma gestão diferenciada, vejamos a argumentação que Cecília Londres Fonseca, também integrante da equipe do GTPI, fornece para a dicotomia material/imaterial quando se trata de patrimônio cultural:

O que importa enfatizar aqui é que, na perspectiva da política de preservação do patrimônio cultural, o uso das categorias "materialidade" e "imaterialidade" é relevante não enquanto critério para distinguir duas espécies distintas de bens culturais, e sim como base para a busca de diferentes formas de preservação. (FONSECA, 2007, p. 69)

De acordo com a exposição da autora, as adjetivações material e imaterial têm finalidade de preservação (gestão). Contudo, se a necessidade de enfatizar a imaterialidade de certos bens tem por objetivo orientar ações diferenciadas de preservação, não sendo, portanto, uma distinção entre bens (e grupos), por que a prática do registro tem se concentrado em determinados grupos sociais? Não teriam os grupos política e economicamente dominantes, as elites, bens de caráter dinâmico e processual (festas, celebrações, formas de expressão etc.) que lhes são referências culturais e passíveis de registro? Da mesma forma, não teriam os povos indígenas e grupos afro-brasileiros bens culturais "materiais" passíveis de tombamento? Para ambas as questões basta querer, pois, como foi explícita e implicitamente sublinhado ao longo deste trabalho, os bens culturais não possuem valor em si, pelo contrário, seu valor é um valor atribuído.

\section{CONSIDERAÇÕES FINAIS}

De toda exposição feita até aqui com o intuito de historicizar a noção de patrimônio imaterial e apreender os seus aspectos centrais, chegamos a alguns resultados (ou ponto de vista) que serão elencados a seguir: em âmbito nacional, o marco no discurso da imaterialidade do patrimônio cultural é a Constituição Federal de 1988; a política federal do patrimônio imaterial é uma construção histórica recente; em contraponto ao privilégio dado ao patrimônio edificado e monumental, o adjetivo imaterial inverte a ênfase das ações do produto para a produção; o ponto central nas ações da política é contribuir para a continuidade dos bens culturais imateriais; 
o adjetivo "imaterial" diz menos sobre um conceito e mais sobre uma estratégia de inclusão de bens e grupos historicamente excluídos das ações oficias do patrimônio cultural; o patrimônio imaterial tem uma intenção compensatória explícita; e, por fim, povos indígenas, grupos de matriz afro-brasileira e comunidades locais têm sido os principais segmentos da sociedade brasileira contemplados pela política do patrimônio imaterial.

Por fim, para encerrar este artigo, lançamos uma a reflexão: quais as implicações da dicotomia que a política de patrimônio cultural brasileira vem consolidando ao naturalizar o patrimônio imaterial como pertencente a determinados grupos sociais e o patrimônio material a outros?

\section{REFERÊNCIAS}

ANDRADE, Mário de. Carta para Gustavo Capanema e anteprojeto para a criação do "Serviço do Patrimônio Artístico Nacional". Revista do Patrimônio Histórico e Artístico Nacional, Rio de Janeiro, nํㅜ 30, p. 271-286, 2002.

BRASIL. Constituição (1988). Constituição da República Federativa do Brasil de 1988. Brasília, DF: Senado; Subsecretaria de Edições Técnicas, 2008.

CANCLINI, Nestor Garcia. O patrimônio cultural e a construção imaginária do social. Revista do Patrimônio Histórico e Artístico Nacional. Rio de Janeiro, nº 23, p. 95-115, 1994.

CHOAY, Françoise. A alegoria do patrimônio. São Paulo: Estação Liberdade, 2006.

CHUVA, Márcia Regina Romeiro. Os arquitetos da memória: sociogênese das práticas de preservação do patrimônio cultural no Brasil (anos de 1930-1940). Rio de Janeiro: Editora UFRJ, 2009.

CUNHA, Manuela Carneiro da. Introdução. Revista do Patrimônio Histórico e Artístico Nacional, Rio de Janeiro, no 32, p. 15-27, 2005.

FONSECA, Maria Cecília Londres. Referências culturais: base para novas políticas de patrimônio. In: MinC/IPHAN/FUNART. O registro do patrimônio imaterial: dossiê final das atividades da Comissão e do Grupo de Trabalho Patrimônio Imaterial. Brasília: Iphan, 20oo. p. 59-69.

Introdução. Revista Tempo Brasileiro, Rio de Janeiro, nº 147, p. 5-9, 2001.

O patrimônio em processo: trajetória da política federal de preservação no Brasil. $2^{\underline{a}}$ ed. rev. ampl. Rio de Janeiro: Editora UFRJ; MinC-Iphan, 2005.

Patrimônio cultural: por uma abordagem integrada (considerações sobre materialidade e imaterialidade na prática de preservação). In: IPHAN/COPEDOC. Cadernos de Estudo do PEP: contribuições dos palestrantes da $1^{\mathrm{a}}$ oficina de PEP. Vassouras, RJ, 2007. p. 69-73.

GONÇALVES, José Reginaldo Santos. A retórica da perda: os discursos do patrimônio cultural no Brasil. Rio de Janeiro: Editora UFRJ; Iphan, 2002. 
INSTITUTO DO PATRIMÔNIO HISTÓRICO E ARTÍSTICO NACIONAL. O registro do patrimônio imaterial: dossiê final das atividades da Comissão e do Grupo de Trabalho Patrimônio Imaterial. Brasília, DF: Iphan, 2000.

. Cartas patrimoniais. $3^{\mathrm{a}}$ ed. rev. e aum. Org. Isabelle Cury. Rio de Janeiro: Iphan, 2004.

. Os sambas, as rodas, os bumbas, os meus e os bois: princípios, ações e resultados da política de salvaguarda do patrimônio cultural no Brasil (2003-2010). 2 $2^{\underline{a}}$ ed. Brasília, DF: Iphan, 2010.

Resolução o01, de 3 de agosto de 2006. In: MinC/IPHAN/FUNART. O registro do patrimônio cultural imaterial: dossiê final das atividades da Comissão e do Grupo de Trabalho Patrimônio Imaterial. 5ํㅡㄹ ed. Brasília, DF: MinC; Iphan, 2012, p. 16-19.

MEC/SPHAN/PRÓ-MEMÓRIA. Proteção e revitalização do patrimônio cultural no Brasil: uma trajetória. Brasília, DF: MEC; Sphan; Pró-Memória, 1980.

MENESES, Ulpiano Toledo Bezerra de. O campo do patrimônio cultural: uma revisão de premissas. In: I Fórum Nacional do Patrimônio Cultural: sistema nacional de patrimônio cultural - desafios, estratégias e experiências para uma nova gestão. Coord. Weber Sutti. Brasília, DF: Iphan, 2012, p. 25-39.

MINC/IPHAN/FUNART. O registro do patrimônio imaterial: dossiê final das atividades da Comissão e do Grupo de Trabalho Patrimônio Imaterial. Brasília, DF: Iphan, 2000.

NOGUEIRA, Antonio Gilberto Ramos. Inventário e Patrimônio Cultural no Brasil. História, São Paulo, v. 26, no 2, p. 257-268, 2007.

SANT'ANNA. Márcia. Patrimônio imaterial: do conceito ao problema da proteção. Revista Tempo Brasileiro. Rio de Janeiro, nㅜㅡㄴ 147, p. 151-161, 2001.

SILVA, Fernando Fernandes. Mário e o patrimônio: um anteprojeto ainda atual. Revista do Patrimônio Histórico e Artístico Nacional, Rio de Janeiro, nº 30, p. 128-137, 2002.

RECEBIDO EM: 02/03/2015

APROVADO EM: 06/05/2015

\section{LEANDRO RIBEIRO DO AMARAL}

Graduado em História pela Faculdade de Ciências e Letras da Universidade Estadual Paulista (Unesp-Assis). Mestre em Preservação do Patrimônio Cultural pelo Instituto do Patrimônio Histórico e Artístico Nacional (Iphan). E-mail: leandro_tuckss@hotmail.com. 